\title{
A Revista Internacional em Língua Portuguesa: da língua à cultura científica ${ }^{1}$
}

\author{
Cristina Montalvão Sarmento \\ Secretária-Geral da AULP (2006-2010; 2014-2016) \\ Professora do Instintuto Superior de Ciências Sociais e Política da Universidade de Lisboa
}

A Revista Internacional em Lingua Portuguesa (RILP) tem sido o veículo da expressão da comunidade que se expressa em português, impulsionada pelo movimento associativo universitário dos anos oitenta e noventa do século XX.

Publicada desde o início da fundação da Associação das Universidades de Língua Portuguesa (AULP) em 1986, foi dirigida primeiro por Maria Helena Mira Mateus, numa inicial série composta por dezassete números, e depois coordenada por José Augusto Seabra, numa segunda série com três exemplares, perfaz trinta títulos, numa terceira série em curso, de cariz institucional e temática.

A sua pretensão de divulgação da língua portuguesa, a longevidade e a expressão intercontinental, fazem desta revista um caso nacional único de internacionalização do centro linguístico original para o universo multilateral das culturas associadas, em torno do vetor comum da língua, alheia às vicissitudes políticas que o tempo impôs e os poderes engendram.

Implícita está a consciência do grau de reconhecimento e influência internacional que as políticas de língua promovem para determinadas línguas ou podem promover para a língua portuguesa. Esta questão traz ainda inerente a atual tese da crescente importância de uma língua como instrumento gerador de poderes, quer ao nível simbólico na construção das identidades, quer ao nível funcional no impacto económico das línguas.

Saber em que medida, uma política de língua ativa e consciente poderá alcançar esse nível de poderes, administrá-los e ampliá-los, terá sido o objetivo dos participantes na vida da revista. A análise do conteúdo favorece a compreensão e a configuração da evolução da rede desses poderes.

\section{Série - Pragmatismo e intenções iniciais}

A Associação das Universidades de Língua Portuguesa, AULP, reúne pela primeira vez em Lisboa em 1988 sob o tema: «Os Problemas da Língua e o Conhecimento das Culturas», história que a RILP regista, anunciando-se no primeiro

1. Este texto, foi publicado em 2010, na Revista Cultura. Revista de História e Teoria das Ideias - Revistas, II Série, Vol. XXVI, Lisboa, Centro de História da Cultura. Na época visava-se o reconhecimento do conteúdo temático que as obrigações quotidianas de Secretária-Geral não tinham permitido. Esta nova versão completa e atualiza a primeira e permitirá aos interessados acompanhar a vida da RILP de forma sintética, que foi, sempre que possível, cruzada com o contexto associativo. 
número, como o resultado natural e pragmático dos dois primeiros anos do esforço associativo da AULP em criar um instrumento de cooperação académica, publicando na RILP todas as comunicações entregues pelos participantes desse encontro.

Nascida no seio do Conselho de Reitores das Universidades Portuguesas, na Cidade da Praia em Cabo-verde, a AULP tem no seu primeiro presidente, António Simões Lopes, à data presidente daquele Conselho e Reitor da Universidade Técnica de Lisboa ${ }^{2}$, um convicto defensor da "generosidade do motivo que era, tão só, o da cooperação e solidariedade, isto é, o da interação e interajuda, extremamente interessadas em serem 'desinteressadas', total e completamente», como afirma na abertura do I Encontro da AULP, texto que abre simultaneamente a RILP em Julho de 1989, criada no Conselho de Administração de Março de 1988, como instrumento pragmático de intercâmbio cultural, científico e de cooperação universitária.

Já no editorial do seu primeiro número a diretora, Helena Mira Mateus, afirmava: «A RILP surgiu como manifestação do desejo de interconhecimento e de intercâmbio de todos os que, na América, na Europa e na África falam português no seu quotidiano, e se preocupam com a sua utilização e o seu ensino. Surgiu ainda a Revista como um modo de aproximar as culturas que na língua portuguesa encontram expressão, ou a moldam para se exprimirem. E se este é o destino do Português, não é mais do que a continuação da sua própria história em que esse destino - como todos os destinos - já estava contido.»

É este percurso de internacionalização do português, em que a história da língua acompanha certos pontos de referência da história mundial que diretamente se invoca, lembrando como a língua portuguesa foi estendida através da África a partir do século XV, aporta à América no limiar do século XVI, em finais desse século, e durante o século XVII, era utilizada como língua geral do litoral africano e como língua franca (indo - português e malaio - português) nos portos da Índia e do Sudoeste da Ásia. Como Europeus e Asiáticos comunicavam em português em extensas regiões da Índia, na Ilha de Samatra e Java e na ilha de Timor. E ainda, como no Japão, Tailândia e na China serviu nas relações políticas, comerciais e religiosas.

Mas é sobretudo, e em particular, pela circunstância do português ser a língua veicular e oficial de Angola, Moçambique, São Tomé e Príncipe, Guiné e Cabo Verde que a RILP se auto justifica. É por ser através da língua portuguesa que se veiculam conhecimentos, na escola e fora dela, no campo da ciência e da cultura,

2. António Simões Lopes teve um papel determinante na emergência da AULP, assim como na sua manutenção. Assume a presidência entre 1986-1989, enquanto Reitor da Universidade Técnica de Lisboa e posteriormente, após uma presidência proposta, mas não concretizada da Universidade Federal do Maranhão durante apenas três meses, reassumirá os destinos da AULP de novo em nome da Universidade Técnica de Lisboa, no seu segundo consulado, no mandato 1993-1996, o que conferirá a estabilidade inicial à AULP. 
que constitui um corpo de questões de complexa e delicada solução, numa rede de relações que o português estabelece com outras línguas, que será primeiramente o objeto do interesse de muitos dos que escrevem na RILP.

Uma terceira dimensão, a que a RILP atende, é ao facto das diferentes literaturas nacionais terem expressão escrita em língua portuguesa, com consequências maiores na deriva da própria língua, no seu enriquecimento e adequação a novas realidades. Como afirma a sua diretora, «Esta é a única perspetiva que nos permite aproximar e diferenciar em português, culturas não portuguesas, e através do português compreender a importância da especificidade dessas culturas. Neste magnifico movimento dialógico a língua portuguesa diversifica-se e preserva-se, mantendo um destino plurívoco que confirma a sua própria história», diálogo fundacional da RILP.

Nestes termos emerge o espaço de troca cultural que toda a revista contém, unindo espíritos que comungam as mesmas inquietações. $\mathrm{O}$ primeiro número abordará em três partes distintas, os problemas da língua e do seu ensino, os conhecimentos das culturas associadas à literatura e à sua dimensão histórico-antropológica e, finalmente, assume-se como instrumento público das atividades da AULP.

Com um conselho editorial intercontinental ainda que sem representante nomeado por Angola, tem representantes no Brasil (Rosa Virgínia Mattos Silva e Atibila T. de Castilho), em Cabo Verde (Alice Gomes Fernandes de Matos), na Guiné-Bissau (Jorge Ampa Cumerlerbo), por Moçambique (Perpétua Gonçalves), em S. Tomé e Príncipe (João Hermínio da Silva Pontífice) e finalmente em Portugal (Manuel Ferreira e Maria de Lurdes Crispim). Com eles estão lançadas as bases de um fórum de discussão científica, apoiado numa complexa estrutura orgânica.

Percorrer a Revista implica compreender como foi solidamente ancorada na dinâmica da sua diretora, Maria Helena Mira Mateus, que preside aos destinos dos dezassete primeiros números, regulares e consecutivos entre 1989 e 1997, oito anos durante os quais não se abstém de, na sua maioria, escrever o editorial, justificando, antecipando ou dando a conhecer ao leitor, a ideia que presidiu ao número, as dificuldades que surgiram, a razão de ser ou, tão só, enumerar os motivos das escolhas.

Estes editoriais não surgem, todavia, como um exclusivo seu e serão entregues aos diferentes organizadores que se sucedem, numa clara expressão de flexibilidade cooperativa, em que será a manutenção de uma estrutura estável e a disposição de conteúdos que lhe dará unidade de sentido e continuidade estrutural.

Numa primeira fase, que se poderia grosseiramente reconduzir aos primeiros quatro números, a RILP emerge como uma revista sobre a língua e a análise dos vários problemas conexos. Assente num - foco -, denominação dada ao tema 
142 | RILP - Revista Internacional em Língua Portuguesa - nº 30 - 2016

principal, formatação que se irá manter até 1997, contém acessoriamente, uma zona de recensões e de notícias, local em que é aberto espaço, por um lado, para a divulgação da bibliografia associada; e por outro lado, para dar a conhecer ou registar as iniciativas académicas relativas aos temas articulados com a atividade da AULP.

Assim se segue um segundo número, publicado em Dezembro de 1989, com editorial assinado por Maria de Lurdes Crispim³ ${ }^{3}$, que salienta como a RILP deve ser «o espaço vocacionado de diálogo intercontinental de língua Portuguesa, sobre a Língua Portuguesa e as culturas que nela se expressam» dedicando o foco à: «Língua vista - Língua ouvida», como sendo o mote da responsabilidade do conselho editorial português, tratam-se alguns aspetos da relação oral/escrito, dos problemas de ensino/aprendizagem de ambos os códigos e da riqueza do seu uso como meio de expressão estética e cultural. São sobretudo as dificuldades de alfabetização que portugueses e brasileiros expressam, neste foco de ouvir e falar. Mas os artigos de Melo e Castro, «O Português, Língua de Experimentar Poesia», ou de Nuno Júdice, «Poesia e Invenção Linguística», com que este segundo número da RILP abre, que lhe dão o carácter universal da 'Alta Cultura' que a caracterizará. Ao assinalar, nas notícias, a realização do I Congresso de Escritores de Língua Portuguesa realizado nos dias 1, 2 e 3 de Março desse ano em Lisboa e ao anunciar o IX Congresso da ALFAL (Associação da Linguística e de Filologia da América Latina), a RILP prossegue na senda de se tornar o veículo informativo dos acontecimentos nacionais e internacionais relativos à língua portuguesa.

Aparentemente o número três da RILP assume a polémica questão de abordar o «Português como língua estrangeira». Como explica Fernando Cristóvão no seu texto de abertura de Julho de 1990, é necessário assumir que a «nossa língua tenha futuro». Emergem as questões relacionadas com a criação de uma política de língua, para a língua portuguesa. Timidamente ainda, assinala-se que por «muitos descobrirem que não éramos só portadores de um património histórico e literário riquíssimo pouco comum em pequenos países, mas também porque a curva demográfica lusófona, francamente ascensional, nos vaticina um futuro promissor», importa que a língua tenha porvir. Ainda que não diretamente focada numa política de língua específica, a matéria do português como língua estrangeira, será bem ancorada em dois artigos, do conselho editorial português, de Maria de Lurdes Crispim e Manuel Ferreira, que abrem a RILP que nos lega exemplos práticos múltiplos da experiência do ensino do português como língua estrangeira, seja em Lisboa, no Brasil ou na Galiza, em Estrasburgo ou na Hungria, em Salzburgo ou em Utreque, ou finalmente, em Perugia. É na pluralidade dos casos práticos

3. Maria de Lurdes Crispim assumirá a Subdireção da Revista a partir do número quinze. Uma figura nova de coordenação emerge a partir do número 12, e será da responsabilidade de Margarida Correia que vem substituir a Redação de Isabel Fraústo que se manterá desde o início até ao número onze. 
ilustrados que as experiências individuais revelam a dimensão da problemática. Finaliza este foco o relatório do 'ensino do português no estrangeiro' realizado pelo grupo de trabalho da $\mathrm{CRSE}^{4}$.

A final, uma breve notícia, refere-se ao II Encontro da AULP, que decorrera em Abril de 1990, na Reitoria da Universidade de Évora, sob o tema «O Papel da Ciência e da Tecnologia nos Processos de Desenvolvimento», modesta referência a que não é certamente alheio o afastamento do tema à questão da própria língua, mas também o facto de se ter iniciado com este Encontro, a publicação autónoma das Atas Científicas ainda que, neste caso, em versão meramente poli copiada.

Este II Encontro da AULP marca o início do esforço de permanência e continuidade estruturada dos temas que a Associação promoverá nos anos subsequentes, nos seus III, IV e V Encontros. Em 1992 (Estoril), a «Ciência e Tecnologia no Desenvolvimento: Os Recursos e as Infraestruturas»; Dois anos depois, em 1994, também no Estoril, o mesmo tema abrigará «O Turismo e o seu Papel no Desenvolvimento dos Países», para em 1995, em Recife, no Brasil, infletir ligeiramente para «O Sistema de Ensino no Processo de Desenvolvimento», temas publicados em coleção autónoma, onde muitos dos responsáveis dos países envolvidos, expressam posições e intenções, o que permite acompanhar o esforço cooperativo da Associação.

Doravante claramente autonomizada, a RILP manterá o foco em especial nos problemas técnicos da língua. $\mathrm{O}$ número quatro será dedicado à «Linguística e ensino das línguas». Como o texto inicial de Helena Silva Duarte permite entrever, o que está em causa é a procura de novos modelos técnicos e científicos com o objetivo de levar os falantes da língua a dominarem os processos de leitura e escrita, pois «não há ciência nem teoria científica que, por si só, forneça pré-preparados os ingredientes para a sua elaboração». Indício da dinâmica da Revista é a criação, neste número, de uma nova secção - Ideias -. Aqui se espelhará a criatividade múltipla de artigos sobre literatura lusófona.

Já a partir do seu único número duplo (cinco/seis) publicado em Dezembro 1991, o âmbito emergirá alargado. Como se a perceção do contacto cultural ganhasse existência. E concretiza um novo campo. O título do foco é sugestivo: «Viagens no português». Ora são as influências Árabes na língua portuguesa, o Japonês ou o Chinês quando em contacto com o português. Ora são considerações sócio-línguisticas sobre o português falado em Moçambique,

4. COMISSÃO DA REFORMA DO SISTEMA EDUCATIVO. Em 1988, fora constituído um grupo de trabalho constituído pelos Professores Aníbal Pinto de Castro, Fernando Alves Cristóvão, João Malaca Casteleiro, Jorge Morais Barbosa, Helena Mira Mateus, Maria Helena Valente Rosa, Mário Quintela Vilela, Vasco Graça Moura e Vítor Manuel Aguiar da Silva (Coordenador) que apresentou à Comissão de Reforma do Sistema Educativo um Relatório de que são publicados extratos, e que dará a dimensão concreta sobre política de língua que a Revista, neste número três, já contém. 
ou os vocábulos de origem africana no espaço da língua portuguesa. Empréstimos lexicais do português no tsonga ou os Quimbudismos no português literário. A ambiguidade do título leva Helena Mira Mateus a intervir no editorial, justificando-o. «O título do FOCO no presente número da RILP tem um duplo objetivo. Apresentar aspetos da influência do português noutras línguas com que estevel está em contacto, e apresentar aspetos da influência dessas línguas sobre o português». É a dimensão da interculturalidade que se manifesta. É possível detetar no português europeu restos da presença árabe, como se encontram no português falado em África os íntimos contactos com as línguas africanas ou como se desvendam no português do Brasil, os apertados laços com as línguas ameríndias. As línguas, como os seres humanos, não crescem em isolamento.

Este número fecha com uma homenagem póstuma ao Professor Luís Filipe Lindley Sintra, cujo percurso académico partiu da literatura, numa altura em que, em Portugal, dele não se tinha autonomizado ainda o estudo da língua. Quando começou a ensinar na Faculdade de Letras de Lisboa não se falava de linguística mas sim de filologia, o estudo da língua portuguesa e a sua aplicação literária eram tão íntimos e inseparáveis que havia só um curso, onde moravam as outras línguas parentes: o curso de românicas. Como aí afirma Helena Mira Mateus, não se tratou apenas de uma homenagem a quem a linguística tanto deve, mas ao seu conceito de universidade, que «não se compadecia com a existência de uma escola monolítica, orquestral, uniformizada. A escola que nos ensinou a viver, em respeito pela liberdade individual, é criadora e tem múltiplos caminhos, vivas discussões, encontros e desencontros, e um querer de comum consciência. A progressiva apropriação científica do nosso falar, da língua que usamos como uma construção do nosso ser-com-os-outros, de nosso ser em liberdade». Talvez daí que Lindley Sintra falasse de uma 'língua românica da terceira geração', quando na sua síntese da História da Língua Portuguesa, este filólogo assim tenha classificado o crioulo de Cabo Verde.

Antecipava-se aqui uma concretização de conteúdo que se manterá nos três números seguintes (sete-oito-nove), em que a intervenção do Brasil também é mais manifesta. Agora o foco incidirá, claramente, nas políticas de língua. Rosa Vírginia Mattos e Silva, de S. Salvador da Bahia, do Brasil, assina o editorial do número sete, quando corria já o ano de 1992, e afirma: «Entra no seu quarto ano de vida a RILP, e este aniversário coincide com o ano em que se comemora ou contesta a descoberta ou invasão da América pela Europa. Entre essas formas antagónicas que retratam formas opostas de avaliar o evento histórico, nenhum melhor foco do que o escolhido para o $n^{\circ}$ 7: Política da língua e políticas culturais. Não é a final esse o foco intrínseco, subjacente ao nascimento e à vida da RILP?».

Aí não se abstêm de se pronunciar aqueles que, desde o início, o tinham compreendido. Artigos individuais, mas de representação institucional, sucedem-se. 
José Augusto Seabra, Embaixador de Portugal na UNESCO. Eduardo Prado Coelho, à data conselheiro cultural junto da Embaixada de Portugal em França ou de António Simões Lopes. Este último, enquanto primeiro Presidente da AULP, assina o artigo com o título inequívoco: Em defesa de uma Política de Língua. Pede-se ainda a palavra às instituições: a Associação Portuguesa de Linguística e o Centro de Linguística da Universidade de Lisboa pronunciam-se. Entidades tão distintas, quanto a Biblioteca Nacional, pela escrita da sua diretora Maria Leonor Machado de Sousa, ou a Lusa, expressam-se e traduzem posições oficiais. Será José Augusto Seabra que melhor sintetiza: «a consciência crescente, mesmo se ainda difusa e propícia a alguma retórica fácil, de que uma política internacional de língua portuguesa deve ser hoje a prioridade das prioridades da nossa politica cultural externa, começa enfim a dar frutos».

Em Março de 1993, o número oito era dado a público com o foco dirigido à «Língua, Línguas. Como falam os escritores» em que Maria Lúcia Lecpecki, que substituíra Manuel Ferreira no conselho editorial português desde o número anterior, vem alertar no texto de abertura, para o que já se manifestara. Sem perder de atenção os problemas da língua portuguesa, das questões da linguística, didática ou da sua pedagogia, tratava-se agora de o fazer de forma interdisciplinar. No caso, «entre linguística e literatura. Como falam os escritores, eis a questão». É a abordagem às utilizações estéticas, ideológicas e de narrativa que a língua regista.

Uma nota informativa no final deste oitavo número, lamenta o falecimento do colaborador da Guiné-Bissau, Jorge Ampa, professor de português e responsável por muitas atividades de animação cultural, elemento essencial para a divulgação da língua portuguesa num país em que, sendo embora língua oficial, o seu ensino enfrenta dificuldades específicas devido ao crioulo e várias línguas étnicas. Será João António de Sá que assegurará a continuidade do conselho editorial na Guiné-Bissau, numa altura em que a situação de guerra ainda não tinha permitido conquistar um membro angolano para o conselho editorial.

Um último número desta segunda fase, o número nove, será dedicado à «Literatura oral e popular», e encerra o ciclo dedicado mais diretamente à Literatura. Maria Del Rosário Albán, em Julho de 1993, no editorial, lembra que quando se fala de literatura, a oralidade não pode ser esquecida. Será a inevitável referência, de como a partir de Portugal, pela ação do Professor Dr. Manuel Viegas Guerreiro que, à frente da linha de ação número quatro do Centro de Estudos Geográficos de Lisboa, conseguiu fazer reconhecer os méritos da produção anónima e coletiva expressa pela voz popular, e por quem tais estudos encontraram ressonância no Brasil. Quando o Professor Viegas Guerreiro fez a sua primeira viagem à Universidade Federal da Bahia, em 1984, aí deixou alimento para um profícuo desenvolvimento do reconhecimento das tradições populares, portuguesas e brasileiras, expressas nos registos de aproximação luso- 
-brasileira no âmbito da literatura oral e popular que nesta RILP transparecem e ficam registados.

Pela sua especificidade, dois números consecutivos inovam a rota da RILP, num justificado tema da responsabilidade de Isabel Hub Faria. «A Criança e a Linguagem», respetivamente em Dezembro de 1993 e em Julho de 1994. Diríamos que estes números, dez e onze, são a expressão da profundidade a que se chegara. Não bastava mais falar sobre o português, mas o seu ensino implicava reconhecer e dar o valor real a cada contexto e situação em que se adquire, aprende, amadurece ou rotiniza o conhecimento de uma língua materna. Afirma-se «Parece imprescindivel saber distinguir, neste final de século e de milénio, o que é necessariamente comum e o que é obrigatoriamente especifico em cada sujeito tornado falante do português, monolingue, bilingue, multilingue, criado em família, em grupo, na rua, na escola, no interior ou na fronteira, a norte ou a sul do Equador»».

E é a par desta consciência, que o foco do número doze, em Dezembro de 1994, não surpreende. «Norma e Variação. Da Língua Portuguesa», é agora a perceção do diversificado complexo cultural que o mundo da lusofonia representa. «São muitas raízes que se encontram e entrecruzam e onde a língua portuguesa se espraia como um denominador comum não uniforme, nem monocórdio, mas refletindo a pluralidade e a multifacetação», palavras de Suzana Alice Marcelino Cardoso no editorial que abre a Revista.

A Política da Língua será doravante mais abertamente assumida. Embora já abordada no número sete, é o número treze que lhe consagra o foco. Segundo Maria Helena Mira Mateus, «numa época em que alguns sectores da inteligenzia' mundial deixaram de olhar as relações económicas como o único, ou pelo menos o mais importante motor da história, numa época em que o estudo das mentalidades voltou a constituir uma forma preferencial de iluminar o percurso do homem, a intervenção explícita no conhecimento e difusão de uma língua tornou-se indubitavelmente uma obrigação política pela qual, no futuro, todos seremos responsáveis.» São em particular as colaborações de Moçambique pelo contexto de utilização do português em contacto com as línguas nacionais, e as experiências relatadas pela colaboração brasileira neste número e que se referem às línguas indígenas do Brasil, que mostram a dimensão universal dos problemas respeitantes a este domínio. E que dizer do artigo, fruto da colaboração alemã, que permite compreender como condições políticas determinadas, alemãs e africanas, estiveram na base do desenvolvimento de uma área científica particular, a Afro-lusitanística, num país não lusófono e não africano.

Atravessávamos ainda o ano de 1995 e já um número especial vinha a caminho, número catorze, dado a público em Dezembro. Se o foco é «O Português 
no Mundo», já não são mais as viagens do português pelo mundo, mas o registo concreto do seu ensino. A aventura crioula, os crioulos do Oriente, Macau no período de transição, Timor, o português que se aprende na Tailândia, no Senegal, na Rússia, na Argentina ou no Reino Unido, entre outros.

A particularidade deste número radica no facto de se inserir nas comemorações dos dez anos da Associação das Universidades de Língua Portuguesa (1986 - 1996). António Simões Lopes, na sua qualidade de Presidente da AULP, vem referir como a RILP «ao colher contributos de praticamente todos os espaços geográficos da lusofonia, contributos que, deliberadamente ou não, permitem um balanço do desenvolvimento da língua portuguesa».

É certo que o tema se justificava no ano em que se constituía a Comunidade dos Países de Língua Portuguesa e na mesma data em que os acordos do Mercosul eram assinados. No entanto, mais dez anos serão ainda precisos, para que a AULP se venha a constituir como Observador Consultivo privilegiado da CPLP.

Finalmente, uma fase final, como que de relacionamento externo que anuncia o futuro, marca o ano de 1996, com os números quinze (Julho) e dezasseis (Dezembro). O primeiro traz a marca da pretensão de expansão maior, quando a representante da União Latina em Portugal, Renée Gomes, assina o editorial, numa revista cujo foco serão «As Linguagens científicas e técnicas». Procura-se realçar o papel que desempenham as linguagens de especialidade, e em particular as terminologias, na fixação da língua e na sua adequação à modernidade, entendendo a língua como fator predominante de manutenção e transmissão da cultura. O segundo será dedicado ao «Português nos meios de comunicação», expressão já dessa abertura ao exterior, reconhecendo-se as inúmeras questões se põem ao uso da língua na rádio, televisão e imprensa.

Um último número, dezassete, já em Julho de 1997, será especialmente dedicado à Literatura infantojuvenil. No editorial, Maria Augusta Seabra Diniz, lembra que a educação das crianças é um dos elementos fundamentais de qualquer processo cultural, e a dedicação de um número da RILP a este foco, significa, antes demais, o reconhecimento da existência de uma literatura de qualidade lusófona especificamente destinada a crianças e jovens. Está em causa o encontro da fantasia do adulto com as experiências e fantasias da criança, dinamizando o encontro do ser humano imaturo com a experiência vivida pelos mais velhos e com a estrutura cultural que organizaram para dar expressão comunicável e partilhável a essa experiência.

Será também este número que marca a saída da última RILP, pela mão de Helena Mira Mateus que, iniciadora do projeto, o vai adotando, filiando e finalmente visa a sua autonomia, prosseguindo na senda de a registar formalmente em seu nome e das suas colaboradoras, numa fase em que as exigências sobre a Edição já se faziam sentir e impunham novas obrigações. 
Adversidades marcam a saída de Helena Mateus. Em desacordo com a manutenção da Revista como propriedade da AULP, esta reage e em ação judicial ${ }^{5}$, contesta o registo nominativo de Helena Mira Mateus e ganha o reconhecimento da propriedade formal sobre a RILP.

Anos idos, desgostos passados, aqui fica o reconhecimento. Sem o trabalho, a sabedoria e o empenho de Maria Helena Mira Mateus, muito não se teria feito pela língua portuguesa, da qual fica o registo em dezassete números exemplarmente consecutivos, numa gestão cooperativa, cuja forma e conteúdo falam por si, malgrado as dissidências na despedida.

\section{II ${ }^{a}$ - Série - A maturidade cultural e os incidentes de percurso}

A intenção institucional de manter a RILP levou a AULP a solicitar ao Embaixador José Augusto Seabra, à data representando Portugal na Roménia, que dela se ocupasse. Este, ao aceitar o encargo, fá-lo na qualidade de coordenador, trazendo a público um primeiro número, em Dezembro de 2000, impresso no Brasil.

Assumindo que de uma segunda série se tratava (vol.1, $\mathrm{n}^{\mathrm{o}} 1$ ), numa altura em que a Presidência da AULP era Moçambicana da Universidade Eduardo Mondlane, na sequência do primeiro mandato brasileiro efetivo, pela mão do Reitor Ruy Pauletti da Universidade de Caxias do Sul (1996-1999), será adotada uma clara posição institucional para a RILP e o editorial de Inguelore Scheunemann de Souza, Reitora da Universidade Federal de Pelotas, Vice-Presidente Brasileira, igualmente o esclarece.

Este número será publicado no Brasil, realizado na gráfica da Universidade Federal de Pelotas e marca um esforço de internacionalização do próprio local de edição, consequência de novos tempos associativos e das dificuldades jurídico-legais do momento. Certamente em resultado dos embaraços de transporte transatlântico, a sua distribuição em Portugal foi restrita e existem apenas alguns exemplares na sede da AULP. As mudanças gráficas realizadas atualizaram-na e à nova figuração e imagem que será adotada, corresponderá um conteúdo mais livre e culturalmente amadurecido.

A dignidade do número um desta nova série espraia-se no seu objetivo. Porque em 2000 o Brasil festejava 500 anos, Inguelore de Souza, vem no editorial afirmar que o Brasil, «com 165 milhões de habitantes, sabe de suas altas responsabilidades na preservação da língua comum, pois esta pertence a todos os usuários». Pois será «Em nome de uma identidade comum e por ocasião do relançamento da RILP, editada pela AULP, que as Universidades do Brasil, Portugal, Angola, Mo-

5. Em ata do Conselho de Administração de 15 de Julho de 1999 se dá conta desta ocorrência. Uma ação judicial proposta pela AULP, intentada pelo gabinete jurídico de Pena, Machete \& Associados, recuperará a propriedade formal da RILP. Na pendência da decisão judicial decide o Conselho de Administração, na mesma reunião, que o próximo número RILP deveria ser publicado no Brasil e o Diretor da Revista deveria ser, por inerência, o Presidente da AULP. 
çambique, Cabo Verde, Guiné-Bissau, São Tomé e Príncipe, Timor Leste e Macau reforçam o génio mais intimo de cada povo, sua alma profunda, está presente, sobretudo, em sua língua».

O texto de José Augusto Seabra, na qualidade de coordenador vem reforçar a afirmação. «A Revista Internacional de Língua Português dedica este seu número especial sob o signo do Quinto Centenário da Descoberta do Brasil, à evocação de domínios e momentos relevantes da vida de um povo que é hoje uma das nações mais importantes da América Latina e do mundo inteiro. No quadro das comemorações oficiais e institucionais dessa efeméride de alcance histórico e civilizacional, não apenas para os dois países irmãos e os da Comunidade linguística a que pertencem, mas para toda a humanidade, pelo seu significado universalista, as Universidades assinalando o acontecimento e mostrando a necessidade de um estudo rigoroso das grandes questões que interessam à prospeção do passado, do presente e do futuro do povo brasileiro, nas suas relações com os outros povos e antes demais com aqueles com quem partilha o idioma comum».

Para o efeito foram convidados muitos autores. Maria Helena da Rocha Pereira, António Paim ou António Braz Teixeira. Miguel Reale, Maria Beatriz Nizza da Silva ou o próprio José Augusto Seabra, constituem um elenco admirável na expressão escrita que concedem ao diálogo luso-brasileiro.

Simultaneamente, a AULP já tinha festejado dez anos de existência e se o VI Encontro (1996) em Lisboa terá ficado marcado pela comemoração e pelo alento da constituição da estrutura política federativa que a CPLP, dez anos depois ao constituir-se, representava, também a realização do segundo Encontro realizado no Brasil, no Rio de Janeiro ${ }^{6}$ (o VII) e o primeiro Encontro realizado em Macau, o VIII em 1998, marcava a período da efetiva internacionalização da Associação, potenciada pela plena participação da franja asiática. Esta última integração fora significativamente apoiada pelo Governador da Região Administrativa de Macau, General Vasco Rocha Vieira e pelo seu Secretário adjunto para a Administração, Educação e Juventude, Jorge Rangel, apoio com expressão financeira que possibilitou a reforma física e a instalação e equipamento da sede própria da AULP em 1999, em edifício arrendado por simbólico valor pela Câmara Municipal de Lisboa.

No entanto na AULP vinha-se então sentindo necessidade de maior vigor de atuação, para além do convívio interuniversitário que os Encontros proporcionavam, de direção de objetivos e de recuperar a participação de associados, ausentes na sequência de um longo debate interno, iniciado em 1999, com a chamada do Ensino Superior Politécnico à participação associativa, pela mão do Secretário-Geral, Dr. Manuel Coelho da Silva. Este tema viria trazer alguma intran-

6. O VII Encontro, realizado no Rio de Janeiro em 1997 é o único não documentado em Atas, pois a recolha a cargo do Arquiteto Gazanau não terá sido entregue ao Secretariado da AULP. 
quilidade à vida associativa, particularmente sentida no XI Encontro em Viseu, então atenuada pela intervenção e ação do Presidente da AULP, Brazão Mazula (1999-2002).

As perturbações sentidas germinaram a convicção da necessidade de mudanças funcionais e nessa sequência, foram aprovadas, em 2001, alterações significativas aos Estatutos, à luz dos quais foi eleita em 2002 uma nova direção, presidida pelo Reitor da Universidade Agostinho Neto de Angola, João Sebastião Teta (2002-2005).

Do ponto de vista institucional, desde 2001 a AULP sofria as mutações que levariam à recomposição do seu Secretariado, uma vez que o Dr. Manuel Joaquim Coelho da Silva, que ocupara funções entre 1986 e 2002, durante dezasseis anos consecutivos num sistema de eleição pessoal, saía, após a alteração estatutária que democratizava a eleição do secretariado, e abandonava funções em desacordo de orientação com sucessivas presidências. Sem prejuízo da sua intensa e longa dedicação, a que a AULP deve vida, a sua saída acarretará consequências que transformarão decisivamente o funcionamento da Associação.

Nesta fase deliberativa da AULP, a RILP manteve-lhe a tónica cultural. Aberta que fora uma segunda série da Revista, um segundo número (Vol.1, n 2) sairá em Abril 2002. Justificado será a sua dedicação à Africa Lusófona. Tal como o número anterior fora consagrado à evocação dos cinco séculos de irradiação histórica do idioma comum no vasto geocultural do Brasil, caberá agora a África a atenção de um número especial, que se auto legitima também na sequência da realização do XII Encontro da AULP, nesse ano de 2002, em Luanda.

Será das línguas, mas também de poesia, romance e escrita africana que esta RILP se ocupa. Uma breve antologia dos poetas africanos de língua portuguesa e o encerramento do número com uma tradução de Manuel Viegas Guerreiro do Conto maconde de tema universal compõem este exemplar tornando-o um dos mais atraentes da coleção.

Simultaneamente, tomará o lugar de Secretário-Geral, Alarcão Troni, (20022005) que acompanhará a Presidência Angolana, mas a sua disponibilidade será interrompida no final desse mandato, pela nomeação subsequente para Presidente do INATEL - hoje Fundação INATEL, prestadora de serviços sociais, nas áreas do turismo social e sénior, do termalismo social, da organização dos tempos livres, da cultura e do desporto populares, com profundas preocupações de humanismo e de qualidade, herdeira histórica da antiga Fundação Nacional para Alegria no Trabalho (FNAT) fundada em 1935.

Os Encontros da AULP emergiam então à luz dos seus associados como fóruns e arenas de discussão em que a centralidade do tema lançado em 2002, no X Encontro em Ponta Delgada, «O Ensino Superior na Sociedade do Século XXI», continha a promessa e acalentava a possibilidade de instituir um espaço lusófono do Ensino 
Superior. Aliás, esta temática fora já anunciada em Maputo, Moçambique, quando o primeiro Encontro realizado do lado do Índico, em 1999, o IX, se realizara em torno do sugestivo tema: «A Universidade em Mudança», no inicio da presidência da AULP da Universidade Eduardo Mondlane cujo Reitor Brazão Mazula foi um impulsionador ativo da presença de Moçambique na Associação das Universidades de Língua Portuguesa e cujo consulado foi marcado pela presença conciliatória e serena de intelectual consagrado às matérias pedagógicas e ao ensino universitário.

De facto, desde 2000, que as reuniões dos dirigentes das Universidades participantes se concentraram na constituição de instrumentos capazes de criar estruturas visando a uniformidade das Instituições de Ensino Superior e Investigação Científica do espaço lusófono com vista à mobilidade crescente de natureza intercontinental.

Os temas dos Encontros refletem-no e concretizam-se. O XIII em 2003, em Macau será dedicado ao «Espaço Lusófono de Investigação do Ensino Superior e Investigação», no ano seguinte em S. Paulo, em 2004, a temática do XIV Encontro ajusta-se «Em Busca de uma Cooperação Académica Efetiva entre os Países da CPLP»; para em 2005, no XV Encontro em Lisboa, se concretizar nos «Novos Desafios no Espaço do Ensino e da Investigação dos Países de Língua Portuguesa». Estas reuniões são sede de importantes reflexões sobre os caminhos a percorrer para instituir um espaço académico lusófono e são acompanhadas da questão transversal da Universidade Virtual de Língua Portuguesa.

Mas são sobretudo, o eco e reflexo, da atenção que as autoridades políticas dão a estas propostas, em particular, a receção dos ministros da comunidade dos países de língua portuguesa, que nas suas reuniões assinam a decisão de criar o Espaço Lusófono do Ensino Superior, em Fortaleza em 2004, constituindo um grupo de trabalho no qual foi incluído um representante da AULP, destinado a preparar a respetiva implementação.

Se as dificuldades de concretização dos objetivos da vida associativa da AULP eram patentes na constituição deste espaço de Ensino Superior, quanto à investigação, como afirma José Lopes da Silva, «Embora tenha sido avançada em reunião de Ministros da Ciência da Comunidade dos Países de Língua Portuguesa, a ideia de criação do espaço de investigação, a sua concretização vai requerer algum tempo. Convém notar que, neste ponto, também não foram plenamente dados, no seio da AULP, todos os passos necessários para uma intervenção efetiva da Associação».

O funcionamento corrente era também dificultado pela sucessão de dois mandatos exercidos a partir de Presidências longínquas da sede internacional, sedeada estatutariamente em Portugal. Todavia será devido ao falecimento súbito de José Augusto Seabra, que esta série da Revista será prematuramente interrompida.

O terceiro e último número, (Vol.1, no 3 ) estava pronto e virá a público in 
memoriam do seu coordenador em Setembro de 2004. Será a José Lopes da Silva, Reitor da Universidade Técnica e Vice-Presidente português da AULP, (20022005), que caberá, na sua nota de abertura, ligar de novo de forma intrínseca AULP e RILP.

Este número é o corolário lógico dos dois primeiros. Na sua aparente anarquia cultural, a ordem é fornecida pelo intuito de representação equilibrada e pelo valor equitativo dados aos diferentes universos culturais em presença. Cabia agora ao Oriente. A Macau, onde se realizara em 2003, o XIII Encontro e a esse espaço onde, conformes as palavras de José Augusto Seabra: «Essa diáspora linguística asiática foi, desde as descobertas até hoje, um elemento preciso de diálogo entre as civilizações orientais e ocidentais, que através de vicissitudes históricas abria caminho à mundialização em curso».

São Poemas Orientais, Sequências Goesas, é o Japão íntimo de Armindo Martins Janeira, ou as Variações sobre uma ideia de Oriente, escritos de autores onde a paixão pelo Oriente se impõe e onde não faltam textos sobre as famosas «Afinidades com o Oriente» pensadas por Agostinho da Silva.

Do empenho e da coordenação de José Augusto Seabra fica-nos um legado marcante, transmutado em três volumes da RILP: um dedicado ao Brasil, outro a África e este último, ao Oriente.

Desde então órfã de coordenação e atenção, a RILP ficará abandonada à sorte institucional, e à inexistência de coordenação na sede ou de conselhos editoriais repartidos pelos vários continentes, onde países e culturas diferentes concorrem pela expressão em português. Apenas três números $(2000,2002,2004)$ em oito anos autenticam o esforço realizado pela manutenção da RILP, mas também a quebra da estrutura antes consolidada.

As vicissitudes da RILP ao longo da segunda série, são certamente intrínsecas, mas são também reflexo de um período de forte debate interno na AULP, de rearranjo de forças e energias, num mundo em mutação que também na AULP se refletiu e a vida associativa espelhou.

No final do mandato da Universidade Agostinho Neto de Angola, em 2005, a presidência da AULP será entregue a Portugal, à Universidade do Algarve (2005-2008), que pela mão do seu Reitor, Adriano Pimpão, se irá ocupar da crise institucional que então assolava o ambiente universitário português, em que Universidades e Institutos Superiores Politécnicos se desencontravam na procura do respetivo lugar no seio do mundo académico português. Controvérsia que se reproduzia no seio da AULP e a que os outros sistemas de Ensino Superior demonstravam estranheza.

A esta escolha da Presidência por Portugal, não será alheio o facto de a Universidade do Algarve ser a única instituição nacional onde convivem aqueles dois tipos de ensino superior, certamente não sem dificuldades, mas com que os seus 
responsáveis estão familiarizados e são contrafeitos a bem gerir.

Assim, em Janeiro de 2006, para Portugal, a questão prioritária da AULP será a recomposição do Conselho de Administração, o que será levado a bom porto pelas conversações do seu Presidente, Adriano Pimpão, com o Presidente do Conselho Coordenador dos Institutos Superiores Politécnicos Portugueses, Luciano de Almeida, hábeis negociadores que permitiram alcançar a estabilidade pelo lado português, não sem sequelas no âmbito associativo, que muitos associados, nomeadamente do Brasil, não tinham sustentado.

Todavia, a característica da Presidência da RILP ser de foro institucional, não permitiu maiores desenvolvimentos até Março de 2006, data de substituição eletiva dos responsáveis da Universidade do Algarve. Controvertida era a questão do lugar de Secretário-geral, que continuava por preencher, suscitando-se dúvidas sobre a necessidade de profissionalização ou não do cargo, tendo o Conselho de Administração decidido que o funcionamento corrente seria assumido pela equipa de colaboradores composta por Gabriel Feio, Analídia Perdigão e Rogério Rei, com a promessa registada em ata de Janeiro de 2006, de que se tentaria estabelecer contactos com vista ao preenchimento do lugar dentro dos condicionalismos financeiros da Associação.

Em Junho de 2006, em Macau realizava-se o XVI Encontro da AULP, o último dedicado à «Organização do Espaço de Ensino Superior Investigação dos Países de Língua Portuguesa», que demarca quase uma década de esforço cooperativo particularmente dirigido, mas também de arrastamento de uma questão, que ganhava intenção política formal cada vez mais significativa, mas também adquiria distância real da prática efetiva, face à pressão sobre o sistema de ensino superior e de investigação português provocado pela profunda reforma europeia que entretanto condicionava a dinâmica e a autonomia institucional.

Simultaneamente, às alterações no espaço nacional português correspondem também dinâmicas internacionais, de integração regional, de crescimento individual ou regressão, dos outros espaços de língua portuguesa.

Se em 2006, nascia a primeira Universidade Pública em Cabo Verde, já em 2008, era suspensa a única participada em 50\% pelo Governo da Guiné-Bissau. Se em S. Tomé e Príncipe a abertura ao crescimento cooperativo se mantém necessário ao pequeno espaço equatorial, em Timor, a cooperação acentua-se sob forma bilateral, a única sustentável face às dificuldades do longínquo novo Estado falante de língua portuguesa. A par, registam-se fortes impulsos governamentais sobre o ensino superior em Angola, cujo impacto certamente se fará sentir nas próximas décadas e que ainda não pode ser mensurado, ao ser descentralizado o ensino superior de Luanda para regiões académico - administrativas com vista à expansão nacional do ensino superior público, que concorre com o manifesto incremento das instituições privadas recém-criadas. Se em Moçambique o cresci- 
mento do Ensino Superior Público e Privado aparentemente se alheia por vezes à unidade linguística, já no Brasil, a Presidência Lula veio incentivar fortes dinâmicas autónomas no ensino superior e na investigação, em particular com acentuada motivação na direção Sul - Sul e incentivando a participação em organizações sul-americanas.

Neste quadro diferenciado e dinâmico que se estabelece e vai emergindo, a AULP prossegue a sua atuação. Se a segunda metade do ano de 2006 foi o ano da estabilização do Secretariado ${ }^{7}$, por proposta da recém reassumida Presidência da Universidade do Algarve, pelo Reitor João Guerreiro, e aprovada na Assembleia-geral de Macau; Já em 2007 a AULP acorrerá a Cabo Verde, onde realiza o seu XVII Encontro, para acolher no seu seio, a recém criada Universidade Estatal, sob os auspícios da «Universidade em Rede», única formulação que parece corresponder aos novos tempos e define também uma instituição criada a partir de uma rede poli mórfica anterior de Institutos de Ensino Superior acolhidos sob uma mesma autoridade académica.

Assumida a necessidade científica de ser a Universidade anfitriã a propor o tema sob o qual se reúnem as Universidades e Instituições de Ensino Superior e Investigação Científica de Língua Portuguesa, será à luz deste principio de democraticidade que doravante se pugnará a atuação da AULP.

A interrupção da publicação das atas dos Encontros Científicos da AULP em 2004, concentrará, na fase inicial, os esforços do Secretariado em disponibilizar os materiais que entretanto dispunha ou recolhe: XIV Encontro em S. Paulo, Brasil, (2004); XV Encontro em Lisboa, Portugal (2005); XVI Encontro, Macau, China (2006) e já sob o título de Universidade em Rede, XVII Encontro da Cidade da Praia em Cabo Verde, todos vindos a público entre Novembro de 2007 e Fevereiro de 2008, num esforço de recuperação que estabilizou estas edições e garantiu o acesso da comunidade aos debates neles realizados.

Estreia-se ainda o interesse em disponibilizar edições úteis e capazes de homenagear as Universidades anfitriãs dos Encontros Científicos da AULP, os que nelas se dedicam à investigação, ou se lhes devotaram ou neles se investiram de corpo e alma de investigadores e humanistas. Assim em Cabo Verde, a reedição de «Santiago, a Ilha e os Homens» de Ilídio do Amaral; Assim, em Brasília, a colaboração com a Universidade Católica Portuguesa permitiu levar ao XVIII Encontro, em 2008, Ano Vieirino, novas fixações de textos, belamente ilustrados, de três Sermões do Padre António Vieira, Embaixador das relações luso-brasileiras. Assim, em Angola, no corrente ano de 2009, no XIX Encontro em Luanda, foi possível renovar o acesso ao público académico, às obras de José Redinha, Etnias

7. A opção será a de nomeação de uma académica sem exclusividade de funções. Será contratado um jovem cabo-verdiano, Suzano Costa a par da saída por reforma de Analídia Perdigão e da indisponibilidade entretanto manifestada de Gabriel Feio, que exercia as funções de secretário-geral interino desde a saída de Alarcão Troni. 
e Culturas de Angola e de José Grandvaux Barbosa, Carta Fitogeográfica de Angola, ambas obras desaparecidas, reedições agora realizadas pela AULP, fruto do empenho conjunto de várias instituições académicas e científicas.

Entre 2006 e 2008, a atualização do logótipo, marca da Associação onde se registam os vinte anos agora decorridos, a atualização de recursos pelo reinvestimento na página eletrónica da AULP, para que a Universidade de Macau concorrera, conseguida a estabilidade financeira e a dignificação externa do edifico da sede, estavam criadas as condições de continuidade saudável da vida institucional da AULP.

A partir da reunião do Conselho de Ministros da CPLP realizada em Bissau em Julho de 2006, a AULP adquire formalmente o Estatuto de Observador Consultivo da Comunidade dos Países de Língua Portuguesa, adquirindo o direito a assistir às reuniões de carácter técnico que se afigurem de interesse para os objetivos que a AULP prossegue, onde, no entanto, funções formalizadas se cruzam e desencontram com as burocracias institucionais.

Em 2008, a necessidade do adiamento de Maio para Setembro, da realização do XVIII Encontro em Brasília, consequência de dificuldades internas vividas pela Universidade Anfitriã e de participação de várias instituições, embaraçou a operacionalidade dos meios do Secretariado, porquanto obrigou à duplicação de meios postos à disposição da organização do Encontro que se viria a realizar sob o lema proposto de: «Ciência, Tecnologia e Desenvolvimento», conforme as Atas publicadas em Fevereiro de 2009 documentam.

Nesse período foram reabertas as relações exteriores da AULP, nomeadamente com a União Latina e com a AUF (Associação das Universidades Francesas) e acentuou-se o esforço para reconstituir um Conselho editorial que permitisse dar continuidade à RILP, mas contactos infrutíferos em Cabo Verde, Angola ou Moçambique não o permitiram. A intenção é clara, os meios restritos e a atividade publicista da Associação intensa. No entanto, em 2008 a Revista Internacional de Língua Portuguesa será dada à estampa.

\section{III ${ }^{\mathrm{a}}$ - Série - Um veículo para a ciência e o esforço pela continuidade}

Podemos afirmar, que fruto desta viragem e organização, foi pela consciência coletiva que envolveu os órgãos da Administração, do Secretariado e pela iniciativa do seu Presidente, que a RILP renascerá.

Assim, em Maio de 2008, como anuncia o Presidente da AULP à data, João Guerreiro, Reitor da Universidade do Algarve, nas palavras de abertura «A Revista Internacional em Língua Portuguesa, órgão da Associação das Universidades de Língua Portuguesa, inicia com este número a sua III ${ }^{a}$ série. Esta nova série representa uma alteração no rumo editorial da Revista. O carácter genérico das séries anteriores é abandonado em benefício da procura de temas que suscitem o interes- 
se da comunidade universitária da CPLP e para os quais se detetam fortes expectativas de criação de redes de investigação ou de pós-graduação, ou do lançamento de programas de mobilidade que abranjam membros da nossa comunidade.»

Não se tratará mais de uma revista sobre a língua portuguesa, mas em língua portuguesa, em que os diferentes estágios da ciência e os desenvolvimentos científicos dos países das comunidades que por ela e através dela comunicam, possam interagir em vários domínios científicos.

A primeira escolha temática recai sobre as Ciências Agrárias e será resultado do empenho e competência de um grupo de trabalho liderado por Fernando de Oliveira Baptista do Instituto Superior de Agronomia da Universidade Técnica de Lisboa em colaboração com Izabel Cristina Takitane, da Universidade Estadual Paulista, do Campus de Botucatu, Brasil, surgindo a público com o título: Agricultura e Desenvolvimento Rural.

Como aí se afirma: «O interesse deste número temático, dedicado às ciências agrárias e aos espaços rurais nos países da CPLP, reside no facto de se poder antever, através da reflexão que os diversos autores fazem sobre essas mesmas realidades, qual o "estado da arte" das preocupações académicas e das pesquisas científicas com incidência naqueles domínios científicos».

Este primeiro número da terceira série - retomará a numeração inicial, pelo que se apresentará sob o número vinte e um. Esforço de diferenciação na continuidade, rendendo-se dessa forma homenagem à longevidade de mais de vinte anos da RILP.

Nas palavras de abertura, prospetava-se ainda o futuro: «As colaborações solicitadas terão sempre a preocupação de oferecer um leque tão alargado quanto possível das inquietações que, em cada momento, permitem refletir as problemáticas dos países CPLP, garantindo que cada número temático possa cumprir o seu papel de catalisador no processo de elaboração científica que decorre da inconformidade universitária».

A atenção focada na agricultura, será tratada a problemática do desenvolvimento rural nos períodos colonial e pós-independência em Angola e Moçambique, e os modelos de desenvolvimento aplicados; Mas são também as especificidades de Cabo Verde; São ainda as questões relativas ao agronegócio, à produção do Biodiesel ou os aspetos relativos à sanidade animal no Brasil; Ou finalmente a procura dos novos caminhos portugueses para o desenvolvimento rural que conciliem as unidades do espaço agroflorestal, com uma gestão multifuncional e adequado quadro institucional. É ainda a experiência de rearticulação do ensino superior das Ciências Agrárias em Timor-Leste. «É uma diversidade que, cremos, pode permitir enriquecer o diálogo e o debate na academia entre os países de língua portuguesa», como refere a nota introdutória dos seus editores.

Reassumida a importância deste veiculo de transmissão e criação de cultura 
científica em português, assim se planeará no conselho de administração de Janeiro de 2009, por proposta do agora Vice-presidente português da AULP, João Guerreiro, Reitor da Universidade do Algarve, repto aceite pela recém eleita Presidência Brasileira, da Universidade Federal de Minas Gerais (2009-2011), com a Reitoria a cargo de Ronaldo Tadêu Pena e ainda a colaboração aceite pela Universidade Agostinho Neto de Angola, que mais um número da RILP se anuncia a partir de uma estrutura com responsabilidade tripartida.

A proposta inicial de a consagrar aos Recursos Hídricos Costeiros. Necessidades de Cooperação Científica, Educação e Perspetivas Futuras com vários tópicos, evoluiu para a centralidade do tema A Gestão da Água e dos Recursos Hídricos, cuja formulação final virá a resultar da compilação dos artigos recolhidos ainda com algumas dificuldades pela equipa da sede e anunciados no seu editorial. Visava-se a arrumação temática e a representação pluricontinental o que tornou a tarefa simultaneamente mais desafiadora e difícil.

Já sob a dinâmica e significativa Presidência do Professor Clélio Campolina Diniz, que sucede na Reitoria da Universidade Federal de Minas Gerais pelo que assume a Presidência da AULP, virá a público o número seguinte (23), dedicado às Cidades e Metrópoles, sob coordenação científica de Roberto Luís de Melo Monte-Môr, do Centro de Desenvolvimento e Planejamento Regional da UFMG, a RILP ganha, então, claros contornos científicos de importância temática significativa, sempre da responsabilidade dos seus editores científicos designados pelas Universidades que o Conselho de Administração atribui.

Os números que se lhe seguem foram sucessivamente coordenados por João Peixoto (Instituto Superior de Economia e Gestão de Lisboa, Portugal) e Duval Fernandes (Pontifica Universidade Católica de Minas Gerais) dedicado ao tema Migrações em 2011, vigésimo quatro número, que definitivamente consagra o interesse brasileiro em se manter nas coordenações científicas da RILP, perdendo-se todavia o esforço temático em favor de uma representação dos vários países integrantes da comunidades de língua portuguesa, o que se manterá nos números seguintes, porventura por falta de orientação em outra direção.

A Segurança Alimentar, assunto caro à nova presidência de Moçambique, recém-eleita da Universidade do Lúrio, sob a Presidência de Jorge Ferrão, será o tema escolhido em 2012, sob coordenação conjunta de Bernardo Pacheco Carvalho (Instituto Superior de Agronomia da Universidade Técnica de Lisboa, Portugal), de João Mosca (Universidade Politécnica de Moçambique) e Walter (Universidade de Campinas, Brasil), que será publicado o vigésimo quinto número. Em 2013, o número 26 segue a mesma linha e, será dedicado ao Turismo, sob coordenação científica de João Albino Silva da Universidade do Algarve, Portugal e de Francisco Anjos da Universidade do Vale de Itajaí, Brasil.

Este número sairá a público já com dificuldades, resultantes da ausência da 
figura tutelar da sede, o secretário-Geral, o que provocou alguma instabilidade editorial. A demissão do cargo de Secretário-geral e a sua substituição temporária por uma secretária executiva, Dra. Teresa Botelheiro (2010-2013), cuja saída em meio de mandato, obrigaram a soluções de recurso, em que só o esforço de continuidade por parte da sede, permitiu a publicação do vigésimo sétimo número dedicado ao Mar ainda no ano de 2014, conforme explica o editorial, publicado já sob a Presidência da Universidade de Macau, representada pelo seu Vice-Reitor, Rui Martins em que se mantém o esforço apenas de representação por países, em detrimento do alinho temático.

Finalmente com o número cumulativo 28 e 29, Rotas e Mercadores, publicado no corrente ano de 2015, firma-se o retorno ao arranjo temático e simultaneamente de representação pluricontinental. Este número regista o regresso da coordenação científica às mãos da Universidade Federal de Minas Gerais, pela designação de Júnia Furtado, e acerta-se a numeração editorial de modo a coincidir com a data dos trinta anos associativos.

Entre 2009 e 2016, a estabilidade da escolha por uma revista temática manteve-se e com este número festivo e historiográfico, comemorativo dos 30 anos da AULP, se encerra esta III Série, a qual coordenada pela equipa da sede, regista os trinta anos de atividade associativa.

Tempos diferentes impõem novos rigores. Motivo pela qual, a RILP foi, entretanto, preparada editorialmente no Secretariado para registo, passou a estar referenciada no catálogo internacional LATINDEX, sistema internacional de informação internacional de revistas científicas, cujas exigências numa primeira fase, impuseram a sua anualidade, um conselho de acompanhamento científico e um processo de revisão de conteúdos que a transformou numa adequada revista científica tendente à circulação internacional.

Numa segunda fase que marcará a IV série a iniciar em 2017, a RILP será submetida à pressão de se converter em semestral, condição para integrar outros catálogos de referenciação científica, nomeadamente o SCIELO a que será submetida para apreciação, cumprindo assim critérios internacionais que tenderão em reverter a RILP numa revista mais atrativa no universo das publicações internacionais.

Estamos em crer que a RILP como meio de comunicação científica determinará e assegurará à Revista a continuidade da sua publicação. Queremos, para concluir, retomar a tese que justificou estas incursões no domínio da Revista Internacional de e em Língua Portuguesa.

A língua enquanto código de cultura partilhado representa um tipo de poder, presente tanto na dimensão política, quanto na económica e mostra que o tipo de poder que a "cultura" veicula dá corpo a tipos de exercício do poder em formatos benévolos que nos comprazemos a preferir em sociedades pacificamente organizadas. 